\title{
THE IMPACT OF THE ELECTRICAL INSTALLATION REGULATIONS, 2009, ON THE SALE AND LEASE OF IMMOVABLE PROPERTY
}

Introduction

The Electrical Installation Regulations, 2009 (hereinafter "the Regulations"), made by the Minister of Labour in terms of section 43 of the Occupational Health and Safety Act 85 of 1993 (hereinafter "the Act") constitute yet another attempt on the part of the South African authorities to regulate the installation and use of electrical installations in buildings. The Regulations, published in terms of R 242 in Government Gazette 31975 of 6 March 2009, supersede the Electrical Installation Regulations, 1992, made by the Minister of Manpower in terms of section 35 of the Machinery and Occupational Safety Act 6 of 1983. They came into operation on 1 May 2009, with the exception of regulation 5(6) which took effect on 1 April 2010.

The 2009 Regulations, like those they replace, impose certain substantive duties on users, lessors and installers of electrical installations. Of particular importance for property owners and lessors is the responsibility for the electrical installation on a property, and the duty to have a valid certificate of compliance in respect of such installation. The old Regulations did not describe these responsibilities and duties in clear terms, resulting in considerable confusion and uncertainty. Disappointingly, the new Regulations are only marginally better in this regard (Bertrand "New Electrical Compliance Regulations make Criminals of a Great Many South Africans" http:// www.bowman.co.za/News-Blog/Blog/New-electricalcompliance-regulationsmake-criminals-of-a-great-many-South-Africans (accessed 2012-10-01). The Department of Labour has published explanatory notes on the Regulations (GN 258 in Government Gazette 35180 of 26 March 2012), but they do little more than merely citing each regulation and stating that it is selfexplanatory.

The Regulations were preceded by a number of drafts ( $R 440$ in Government Gazette 23323 of 15 April 2002 and R 1161 in Government Gazette 28293 of 9 December 2005) which, reportedly, elicited "acrimonious debate" (Greager "The new Electrical Installation Regulations" April 2009 Vector 6), even the possibility of litigation involving the Electrical Contractors' Association of South Africa (hereinafter "ECASA") and the Department of Labour (Venter "Electrical Contractors in Battle with State over Certificates" http://www.engineeringnews.co.za/article/electrical-contractors-in-battle-withstate-over-certificates-2004-08-20 accessed 2012-10-12). However, the main points of dispute were not so much the impact of the Regulations on the sale and lease of immovable property but revolved around issues affecting the electrical contracting industry and its stakeholders (see, eg, the 
Eastern Cape ECA Newsletters of May 2007 and August 2008; Yelland and Botha "The Dangers of Policing Electrical Installations by Unaccredited Government Agents" http://dailymaverick.co.za/article/2011-06-09-the-dan gers-of-policing-electrical-installations-by-unaccredited-government-agents (accessed 2012-10-02).

This note focuses on the requirements to be met in terms of the Electrical Installation Regulations, 2009, in relation to the sale and lease of immovable property, residential premises in particular. To place the discussion in perspective it is firstly necessary to examine briefly the objective and scope of the Regulations, having regard to certain key definitions contained in the Occupational Health and Safety Act and the Regulations. Any word or expression to which a meaning has been assigned in the Act has the same meaning for the purposes of the Regulations.

\section{Objective and scope of the regulations}

The objective of the Regulations is not stated specifically in the Regulations themselves, nor is there a clause in the Act describing the aim and purpose of the Act as such. The long title of the Act reads as follows:

"To provide for the health and safety of persons at work and for the health and safety of persons in connection with the use of plant and machinery; the protection of persons other than persons at work against hazards to health and safety arising out of or in connection with the activities of persons at work ..."

It is not necessary for present purposes to analyse this in detail. Suffice to state that, based on the long title, the Act is clearly aimed at protecting the health and safety of persons who themselves use machinery or plant (as defined in the Act) or who are exposed to health and safety risks arising from the use thereof by others. On this approach, taking into account certain key definitions (see below), the main objective of the Electrical Installation Regulations is plainly to provide for the health and safety of persons in connection with the use of the electricity installation installed in any building, partially or fully constructed.

The necessity for the control measures is evidenced by statistics compiled by the National Fire Protection Association. They reveal that approximately 3600 formal house fires were recorded in South Africa in 2010, causing the deaths of 60 people and a monetary loss of more than R1,3 billion. Over the period 2005-2009 about half of such fires had their origins in electrical distribution or lighting-equipment problems (http://ecasa.co.za/sellers-cau tioned-over-electrical-compliance-certification/ accessed 2012-10-01).

The scope of the Regulations is not expressly stated but is delineated by certain key definitions in the Regulations and the Act. This is discussed next.

\section{$3 \quad$ Key definitions}

\section{"Premises" and "building"}

The Regulations, despite being rooted in labour-related legislation, are not confined to the use of electrical installations at places of work. They apply to 
electrical installations in or on "premises", defined in the Act to include "any building". The latter expression is defined as

"(a) any structure attached to the soil;

(b) any building or such structure or part thereof which is in the process of being erected; or

(c) any prefabricated building or structure not attached to the soil."

The Regulations are not restricted to electrical installations in buildings used for commercial and industrial purposes, but apply to such installations in all types of buildings including ordinary residential dwellings. The buildings may be partially erected, and need not necessarily be permanent fixtures. Thus the Regulations apply to electrical installations in prefabricated outbuildings such as wendy houses, which are commonplace throughout South Africa.

\section{"Electrical installation"}

The Regulations define an "electrical installation" as

"any machinery, in or on any premises, used for the transmission of electricity from a point of control to a point of consumption anywhere on the premises, including any article forming part of such an electrical installation irrespective of whether or not it is part of the electrical circuit, but excluding

(a) any machinery of the supplier related to the supply of electricity on the premises;

(b) any machinery which transmits electrical energy in communication, control circuits, television or radio circuits;

(c) an electrical installation on a vehicle, vessel, train or aircraft; and

(d) control circuits of $50 \mathrm{~V}$ or less between different parts of machinery or system components, forming a unit, that are separately installed and derived from an independent source or an isolating transformer."

"Machinery" is defined in the Act as "any article or combination of articles assembled, arranged or connected and which is used or intended to be used for converting any form of energy to performing work, or which is used or intended to be used, whether incidental thereto or not, for developing, receiving, storing, containing, confining, transforming, transmitting, transferring or controlling any form of energy".

"Point of control" and "point of consumption" are defined in the Regulations (reg 1). The first means "the point at which an electrical installation on or in any premises can be switched off by a user or lessor from the electricity supplied from the point of supply, or the point at which a particular part of an electrical installation on or in any premises can be switched off where different users occupy different portions of such premises". "Point of supply" means "the point at which electricity is supplied to any premises by a supplier", the latter being any person who supplies or contracts or agrees to supply electricity to an electrical installation. In urban areas this is usually the local municipality.

A "point of consumption" is "any point of outlet or the supply terminals of machinery which is not connected to a point of outlet and which converts electrical energy to another form of energy: Provided that in the case of machinery which has been installed for any specific purpose as a complete 
unit, the point of consumption shall be the supply terminals which have been provided on the unit of machinery for that purpose". "Point of outlet" means "any termination of an electrical installation which has been provided for connecting any electrical machinery without the use of tools".

In laymen's terms an electrical installation in a building thus comprises the wiring ("machinery") between the main board ("point of control"; sometimes also loosely called "switchboard") and the plug points and other electricityconnection points in a building ("points of consumption"), as well as anything forming part of the wiring, such as the circuit breakers contained in the main board, earth-leakage units, isolator switches and the plug and connection points themselves. It excludes the municipal electricity meter in a building (this being at the point of supply) as well as electrical appliances plugged in or connected to points of consumption, such as stoves, geysers, air conditioning units, swimming-pool and borehole pumps, etcetera. Such appliances are not covered by the definition of "electrical installation" since they are not machinery used for the transmission of electricity from a point of control to a point of consumption, and they do not form part of the electrical installation as such. For the purposes of the Act an appliance could arguably be a "plant", which is defined to include "fixtures, fittings, implements, equipment, tools and appliances, and anything which is used for any purpose in connection with such plant". However, the definition of electrical installation does not cover "plants".

\section{"User"}

For the purposes of the Act a "user" means "in relation to plant or machinery .... the person who uses plant or machinery for his own benefit or who has the right of control over the use of plant or machinery, but does not include a lessor of, or any person employed in connection with, that plant or machinery" (s 1 of the Act). The occupier of a house such as a lessee, or a purchaser who has moved in before transfer, is therefore the user of the electrical installation, as well as the owner of a property (vacant or otherwise) to the extent that he or she has retained the right of control over the use of the electrical installation. A lessor, however, is not a user regardless of his or her control over the use of the electrical installation.

\section{Responsibility for electrical installations}

\section{The position under the Electrical Installation Regulations, 1992}

Regulation 2 of the 1992 Regulations reads as follows:

"Responsibility for electrical installations

2(1) The user or lessor of an electrical installation, as the case may be, shall be responsible for the safety, safe use and maintenance of the electrical installation he uses or leases.

(2) The user or lessor of an electrical installation, as the case may be, shall be responsible for the safety of the conductors connecting the electrical installation to the point of supply in the case where the point of supply is not the point of control." 
As explained above, a "user" includes not only the person actually making use of the electricity supply to the property, but also the person having the right of control over the use of plant or machinery, other than a lessor. However, although not a "user" a lessor was nevertheless in terms of regulation 2 of the 1992 Regulations responsible for the safety, safe use and maintenance of the electrical installation in the premises. This begged the question: who was actually responsible for the safety, safe use and maintenance of the electrical installation in leased premises? The same question arose in situations where the owner and purchaser were both users such as where the building had been sold and the purchaser moved in before transfer.

The Regulations did not impose the relevant statutory duty on both the owner and the purchaser, or both the lessor and the lessee, but on either of them in the alternative. Presumably the parties could by agreement allocate the duty to one of them but it was not clear what the position was in the absence of such agreement. For example, could the lessor contend that the lessee was responsible for the safety of the installation since he was the user, or could the lessee maintain that it was the lessor's duty as expressly stated in regulation 2(1)? The question was not simply academic, since a contravention of regulation 2 constituted an offence for which a fine or imprisonment could be imposed.

\section{The position under the Electrical Installation Regulations, 2009}

The difficulty referred to above apparently did trouble the drafters of the revised regulations, although no attempt to rectify the matter was made in the 2002 draft. The 2005 draft retained the principle that the responsibility for the safety of an electricity installation rested with the user or lessor, but a new subregulation was added stating that "(w)here there is no written undertaking by the lessee to ensure compliance and the safety of the electrical installation he or she leases, the owner of the electrical installation shall be deemed to be the user of such electrical installation". However, the wording was not carried over to the final regulations. Instead, regulation 2 now reads as follows:

\section{"Responsibility for electrical installations}

2(1) Subject to subregulation (3), the user or the lessor of an electrical installation, as the case may be, shall be responsible for the safety, safe use and maintenance of the electrical installation he or she uses or leases.

(2) The user or lessor of an electrical installation, as the case may be, shall be responsible for the safety of the conductors on his or her premises connecting the electrical installation to the point of supply in the case where the point of supply is not the point of control.

(3) Where there is a written undertaking between a user or lessor and a lessee whereby the responsibility for an electrical installation has been transferred to the lessee, the lessee shall be responsible for that installation as if he or she were the user or lessor."

The regulation invites the following comments: 
$\Theta$ The outcome of subregulations (1) and (3) is that a lessee assumes responsibility for the safety, safe use and maintenance of the electrical installation only if this is agreed to in writing between the lessor and lessee, or between the user and the lessee. In practice an agreement between the lessee and the user would not be the norm, but it may presumably arise in situations where the premises are sublet on the basis that the lessee must enter into an agreement with the owner (being the "user" of the electrical installation) to take responsibility for the safety and maintenance of the installation.

$\Theta$ In cases where a lessee has not agreed in writing to assume the responsibility in relation to the safety, safe use and maintenance of the electrical installation, the responsibility rests with the lessor (or owner, as the case may be). However, it is not clear what a lessor can or should do to ensure that the lessee uses the electrical installation in a safe manner, since he or she might not be aware of the lessee's actual use of the installation (see Greager April 2009 Vector 6). An appropriate clause ought to be included in the lease agreement but it is doubtful whether this would suffice to discharge the lessor's responsibility. Regular inspections of the premises may well be called for.

$\Theta$ The new regulation does not address the situation where a purchaser takes occupation of a property before transfer, and the question remains whether in such instances the responsibility for the safety and maintenance of the electrical installation rests with the seller as owner or the purchaser, both being "users".

$\Theta$ Subregulation (2) deals with the responsibility for the safety of the conductors connecting the electrical installation to the point of supply in cases where the point of supply is not the point of control. It is not entirely clear who carries the responsibility in question where a property is let, or where there is more than one user (such as where a purchaser moves in before transfer). The subregulation has not been made subject to subreg (3), indicating that a lessee may well be saddled with the responsibility even in the absence of an agreement contemplated in subregulation (3).

$\Theta$ Subregulation (1) burdens a user or lessor of an electrical installation with three distinct responsibilities, namely (a) the safety of the installation, (b) the safe use thereof, and (c) the maintenance of the installation. Subregulation (3) creates the opportunity of shifting these responsibilities to the lessee. While no reasonable lessee could validly object to having a duty to use the installation in a safe manner, the same cannot necessarily be said in relation to the other two duties. Depending on the state of an electrical installation the costs of keeping it safe and in working condition could be considerable, especially in older buildings where the wiring may have deteriorated necessitating replacement. However, not all lessees are necessarily aware that the risk will be theirs if they sign a lease agreement containing a clause burdening them with the safety and maintenance obligations. In practice lease agreements are often standard, pre-printed documents and in many instances lessees sign these in good faith without reading them. In some cases a lessee trapped by an electrical safety and maintenance clause may seek the protection afforded by the Consumer Protection Act 68 of 2008, but this is new 
ground and it remains an open question to what extent a Court will come to his or her assistance.

$\Theta$ A lessee may be willing to agree to bear the responsibility in relation to the safe use of the electrical installation, but not the responsibility of maintaining the installation and ensuring its safety. However, it is not clear whether a lessee may agree to assume only some of the duties mentioned in subregulation (1), but not all three. In principle there appears to be no reason why this cannot be done.

$\Theta$ ECASA, through its National Director, has pointed out that any property can have electrical problems regardless of how old it is, such as poor earth work, illegally installed additions, open joint boxes, unreadable ratings on circuit breakers, a lack of labelling on the distribution boards, faulty light switches and socket outlets, and illegal open wiring (see: "Sellers Cautioned over Electrical Compliance Certification" http://ecasa. co.za/sellers-cautioned-over-electrical-compliance-certification/ accessed 2012-10-01). In addition, undersized wiring may cause fires. This begs the question: if a lessee has assumed the responsibility for the safety and maintenance of the electrical installation, can he or she be held responsible for safety and maintenance issues that arise from an installation that was already unsafe at the time when the lease commenced?

$\Theta$ In Gauteng regulation 7 of the Unfair Practices Regulations promulgated under the Rental Housing Act 50 of 1999 specifically imposes on lessors of dwellings the duty to maintain the electrical system in good order and repair. Under that Act (s 5(6)(g)) a written lease must set out the duties of the lessor and the lessee, and this "must not detract from the provisions of the ... regulations relating to unfair practice". Accordingly, although regulation 2(3) of the Electrical Installation Regulations, 2009 allows a lessor to contract out of the duty to maintain the electrical installation by shifting the responsibility to the lessee, it is not entirely clear to what extent this is permissible in respect of leases of dwellings in Gauteng.

From a practical point of view an approach equitable to both a lessor and a lessee in most instances would be that the lessee assumes the responsibility for the safe use of the installation while the lessor retains the responsibility for the safety and maintenance of the installation. A lessee would be well advised not to assume the responsibility for the maintenance and safety of the electrical installation without first obtaining from the lessor a certificate of compliance $(\mathrm{COC})$ recently issued in respect of the entire installation.

\section{$5 \quad$ Certificate of compliance: The position under the Electrical Installation Regulations, 1992}

Regulation 3(1) of the 1992 Regulations made it compulsory for every user or lessor of an electrical installation to have a valid COC in respect of the entire installation, subject to certain exceptions (see below). A COC was defined as "a certificate in the form of Annexure 1 issued by an accredited person in respect of an electrical installation or part of an electrical installation". Accredited persons were persons registered in terms of 
regulation 9 as electrical testers for single phase, installation electricians or master installation electricians. Only an accredited person could issue a COC and only after having satisfied himself or herself by means of an inspection and test that an electrical installation complied with the applicable safety standards or, in the case of an electrical installation existing prior to the coming into force of the regulations (23 October 1992), that it was reasonably safe. (Reg $7(1))$. An accredited person had to refuse the issue of a COC if any fault or defect was detected in any part of the electrical installation (reg 7(2)).)

The underlying aim was obviously to promote the health and safety of electricity users by preventing them from being exposed to electrical installations that were not safe. While this was undoubtedly a praiseworthy objective, the Regulations contained a number of loopholes hampering their effectiveness. The drafting, too, was inelegant, causing confusion amongst sellers, buyers, estate agents and conveyancers. The following is a brief summary:

$\Theta$ All users or lessors of electrical installations installed in buildings on or after 23 October 1992 had to have a valid COC in respect of such installation. Users or lessors of electrical installations installed prior to that date were exempted from this requirement, but a COC for the whole installation had to be obtained if

(a) any change or addition was made to the installation on or after 23 October 1992, for example by reason of renovations or extensions to the building; or

(b) ownership of the building changed hands after 1 January 1994.

(Reg 3(1) read with reg 3(3)).

$\Theta$ Suppliers of electricity (municipalities or Eskom) were prohibited from connecting an electrical installation to the electricity supply unless a COC for the installation had been produced to them by the users concerned. This did not apply where the electricity supply was disconnected for nonpayment of the electricity account, or where there had been a change of lessee but not of ownership (reg 6(2)).

$\Theta$ A validly issued COC never lapsed but remained valid indefinitely, except where any addition or alteration had been effected to the electrical installation in question. In such an event the user or lessor had a choice: he or she could obtain either a COC for the addition or alteration only or a new COC for the whole installation. The new certificate again remained valid indefinitely, unless changes or additions were again made after it had been issued, in which event the user or lessor again had the choice mentioned earlier (reg 3(1) read with reg 3(3)).

$\Theta$ A valid COC could be transferred from one user or lessor to the next, in perpetuity (see reg $3(1)$ ).

$\Theta$ A major difficulty experienced in practice related to the validity of COCs. Some registered electricians issued COCs without ensuring compliance with the applicable safety standards, or issued them using the wrong form. Particularly problematic was the issue of COCs by unregistered electricians, masquerading to be qualified to do so: see "Sellers 
Cautioned over Electrical Compliance Certification" (http://ecasa.co.za/ sellers-cautioned-over-electrical-compliance-certification/ accessed 201210-01). Unbeknown to bona fide property owners the COCs in all these instances were invalid. Linked to this was the situation where an owner was issued with a $\mathrm{COC}$ and thereafter effected renovations or repairs impacting on the electrical installation. On a sale of the property the original $\mathrm{COC}$ was simply handed over to the purchaser, the latter being unaware that the COC did not cover the changes to the electrical installation: see http://www.theforumsa.co.za/forums/showthread.php/53 10 -New-electrical-installation-regulations $? \mathrm{~s}=84 \mathrm{a} 780 \mathrm{f} 7 \mathrm{~d} 36 \mathrm{ff} 0 \mathrm{~d} 54 \mathrm{f} 188 \mathrm{f} 3 \mathrm{~d} 0$ 9ccd2bc (accessed 2012-10-02).

$\Theta$ After 1 January 1994 a COC had to be obtained in all instances where ownership of a property changed hands and the transferor did not have a valid COC. Two issues confused the matter: firstly, the regulations did not state explicitly who had to obtain the COC; secondly, it was unclear at what stage the COC had to be obtained. On a sale of a property the question thus arose whether the seller was to obtain the certificate prior to transfer based on the fact that he or she was the user up to the time of transfer, or whether it was the purchaser's responsibility to do so after transfer based on the fact that he or she was now the user of the electrical installation. Some conveyancers took the view that it was an "urban legend" or "urban myth" that a dwelling could not be transferred without a COC (see http://www.snymans.com/news accessed 2011-06-03; http://w ww.theforumsa.co.za/forums/showthread.php/5310-New-electrical-install ation-regulations? $\mathrm{s}=\mathrm{d} 522254 \mathrm{baa} 46816 \mathrm{~b} 181 \mathrm{a} 1975 \mathrm{c} 7 \mathrm{~d} 06790$ accessed 2012-10-02). A number of estate agents followed this approach (http:// www.somersetwestproperties.co.za/elec_comp.asp accessed 2 October 2012) but others believed that a property could not even be marketed for sale without a valid COC (http://forum.tpn.co.za/topic273-electrical-certifi cate-of-compliance.aspx; http://www.eprop.co.za/index.php/news/item/79 03-Electrical-Compliance-Certificate-An-essential-part-of-a-property accessed 2012-10-02). Another view (supported by some leading estateagency firms and conceyancers) was that the regulations made it mandatory for a seller to deliver to the purchaser a valid COC before transfer: http://www.property24.com/articles/electrical-compliance-madesimple/9613; http://www.eepublishers.co.za/images/upload/ECA-SA-Safe ty-Legislation-EnforcementB.pdf; http://www.meumannwhite.co.za/newsdetails/19/ (accessed 2012-10-02). There was also the contention that most estate agents and transferring attorneys were not aware that $\mathrm{s} 10(4)$ allowed the seller and buyer to enter into a written agreement whereby the seller transferred the COC obligation to the buyer: http://www. eepublishers.co.za/images/upload/ECA-SA-Safety-Legislation-Enforce mentB.pdf accessed 2012-10-02.

Given the repeal of the 1992 Regulations it serves no purpose at this stage to analyse the merits of the views referred to above. Suffice to state that the confusion that existed did little to promote property practitioners' confidence in the dispensation. Consumers, too, became disillusioned by some electricians' corrupt activities and incompetence, triggering comments on the internet to the effect that a COC "is not worth the paper it's written on" and had been "designed to create work for the electrical industry at the 
expense of the purchaser or seller" (http://www.theforumsa.co.za/forums /showthread.php/5310-New-electrical-installation-regulations?s=d522254baa 46816b181a1975c7d06 790 accessed 2012-10-02).

In the circumstances much was expected of the 2009 Regulations.

\section{Certificate of compliance: The position under the Electrical Installation Regulations, 2009}

Under the new Regulations a COC essentially has the same meaning as previously, except that every certificate now has a unique number and is issued by a "registered" person instead of an "accredited" person. It is defined as

"(a) a certificate with a unique number obtainable from the chief inspector, or a person appointed by the chief inspector, in the form of Annexure 1, and issued by a registered person in respect of an electrical installation or part of an electrical installation; or

(b) a certificate of compliance issued under the Electrical Installation Regulations, 1992."

A "registered person" means a person registered in terms of regulation 11 of the Regulations or a person registered under regulation 9 of the 1992 Regulations as an electrical tester for single phase, an installation electrician or a master installation electrician.

The new Regulations retain the fundamental principle that, subject to certain exceptions, users or lessors of electrical installations must have valid COCs, issued by registered persons. There are, however, certain new provisions impacting materially on property transactions. Regrettably not all the confusion that existed previously had been satisfactorily addressed. In addition, the wording of the Regulations is again not entirely clear and issues relating to the validity of COCs may now arise which did not exist previously.

The new dispensation is best explained under the following headings:

\section{Duty of users or lessors to have certificates of compliance}

The provisions of regulations 3(1) and (3) of the 1992 Regulations discussed above have largely been carried over to regulation 7 of the 2009 Regulations, subject to a few relatively minor changes. The position now is the following:

(a) The general rule is that every user or lessor of an electrical installation installed on or after 23 October 1992 is obliged to have a valid COC for that installation in the form of Annexure 1, which must be accompanied by a test report in the format approved by the chief inspector (reg 7(1)). Users or lessors of installations installed before that date are exempted from this requirement unless

(i) there is (or had been) a change of ownership of the property after 1 March 1994; or

(ii) any addition or alteration is effected to the electrical installation. 
If either of the events mentioned in (i) or (ii) occur (or did occur) the user or lessor must obtain a COC in respect of the whole installation (reg $7(3))$.

(b) Every user or lessor who is obliged to have a valid COC must on request produce the certificate to an inspector, a supplier or, subject to regulation $4(1)$, an approved inspection authority for electrical installations (reg $7(2)$ ). In terms of regulation 4(1) an approved inspection authority for electrical installations may enter premises and conduct an inspection, test or investigation only when contracted to do so by the chief inspector or provincial director for a specific electrical installation, or upon request by the user or lessor of an electrical installation.

(c) Where any addition or alteration is effected to an electrical installation for which a COC has been previously issued, the user or lessor in question must obtain a new COC for at least the addition or alteration (reg 7(4)).

(d) No person shall connect or permit the connection of any completed or partially completed electrical installation to the electricity supply unless it has been inspected and tested by a registered person and a COC for that electrical installation has been issued. This does not apply where the electricity was disconnected for the non-payment of the electricity account or where there has been a change of tenant but not of ownership (reg 8(2)).

These provisions are relatively straightforward and clear, subject to the following:

$\Theta$ Regulation $7(1)$ requires of a user or lessor to have a valid COC. However, although the expression COC is defined (see above) there is no provision stating expressly what the requirements for a valid $\mathrm{COC}$ are or under what circumstances a valid certificate would become invalid see the discussion below.

$\Theta$ The Regulations do not impose a duty on both a lessor and a user to have a COC; what is required is that either of them must do so. Clearly, where the owner is the user of the electrical installation and nobody else is in occupation of the property in question, the owner must have the COC. What is less clear, however, is on whom the duty rests in situations where the owner lets the property while retaining control over the electrical installation. In such a scenario the owner is not only the lessor, but both he/she and the lessee are "users". The same issue arises where an owner has sold the property and the purchaser has moved in before transfer on the basis that control over the electrical installation passes from the owner to the purchaser only on registration of transfer: both the owner and the purchaser are "users" of the electrical installation.

In the case of a lease reg 7 must presumably be read with reg 2(3) (discussed above), the outcome being that the owner/lessor will be burdened with the duty to obtain a COC unless the lessee has agreed in writing to assume responsibility for the safety, safe use and maintenance of the electrical installation. However, the Regulations do not offer the same solution in a case where a purchaser has moved in before transfer - accordingly, the only practical way to deal with the matter would be by way of agreement between the parties. 
$\Theta$ A user or lessor who has no $\mathrm{COC}$ in circumstances where he or she is obliged to have one commits an offence (reg 15). However, neither the Occupational Health and Safety Act 85 of 1993 nor the Regulations prohibit any such person from entering into a sale or lease agreement see below. The validity of a sale or lease agreement is therefore not dependent on either of the parties complying with the duty to have a COC.

\section{Change of ownership}

Regulation 7(5) reads as follows:

"Subject to the provisions of section 10(4) of the Act, the user or lessor may not allow a change of ownership if the certificate of compliance is older than two years."

The provision is problematic and requires closer attention:

$\Theta$ It is not clear what the regulation aims to achieve. One possibility is that there was a concern that an electrical installation may deteriorate over a two-year period, hence a new inspection and test is called for if the last one was done more than two years before transfer. It may also have been the intention to at least limit to some extent the practice whereby property speculators simply deliver to a purchaser a COC issued in respect of the electrical installation some time in the past, despite the fact that extensive alterations had been made to the installation in the meantime. Whatever the main driving force was, the policy consideration underlying the regulation is obviously that a COC older than two years may convey the impression that the electrical installation in question is safe, while in actual fact the possibility exists that it may not be the case.

$\Theta$ Regulation 7(5) applies to not only a user but also a lessor. This covers the situation where a property owner has let the premises on the basis that the lessee take over the control of the electrical installation. In such a case the owner is no longer the user of the electrical installation, but the lessor. Being the owner, the lessor may not allow a change of ownership if the current COC held by him or her is older than two years. It is not clear, however, how the regulation is to be applied in cases where neither the owner nor the lessor is the user of the electrical installation (control thereof vesting in the lessee), and the lessor is not the owner of the premises.

$\Theta$ The two-year limit applies only when a property is transferred, not when it is let. A COC issued to a lessor can be handed over to successive lessees in perpetuity and to that extent it remains usable by the lessor indefinitely. This begs the question: if user safety was the main concern why does regulation 7(5) not cover leases too?

$\Theta$ In practice issues relating to COCs are usually, but not always, regulated by agreement between sellers and purchasers of immovable property. It may be agreed that the seller is to deliver to the purchaser a valid COC on or before a certain date, or it may be stipulated that the seller has no duty to do so and that the responsibility to obtain a valid COC rests on the purchaser. Disputes rarely arise where the relevant agreement of sale 
deals with the matter properly. The situation becomes more problematic, however, during the negotiation stages of a sale or when the sale agreement is silent in this regard, the key question then being whether the seller is legally obliged to deliver to the purchaser a valid COC on or before transfer.

In terms of regulation 7(5) a user or lessor "may not allow a change of ownership" if the current COC held by the user/lessor is older than two years, subject to section 10(4) of the Occupational Health and Safety Act 85 of 1993. The wording is inelegant but the way it is understood in practice (see below) is that, unless the purchaser of immovable property housing an electrical installation agrees to obtain a new COC, the owner is prohibited from transferring the property to the purchaser in situations where he or she is in possession of a COC older than two years. The prohibition on transfer needs to be understood properly:

(a) In cases where an agreement of sale imposes a duty on the seller to deliver to the purchaser a valid $\mathrm{COC}$ on or before transfer, the seller cannot fulfil this duty by delivering to the buyer a COC older than two years. In fact, transfer is prohibited. The seller's only option is to obtain a new COC.

(b) In cases where an agreement of sale makes no provision for obtaining a COC by either the seller or buyer, transfer is prohibited if the seller has a valid $\mathrm{COC}$ in respect of the electrical installation and such $\mathrm{COC}$ is older than two years. The purchaser may demand transfer and if the seller cannot proceed because of the prohibition, he or she would be in breach of contract. However, regulation 7(5) does not empower the purchaser to hold the seller liable to obtain a new COC.

(c) Regulation 7(5) does not introduce a general rule that all transfers of immovable property are prohibited unless a COC has been issued. It neither confers a statutory right on each and every purchaser to hold the seller responsible for delivering to the purchaser a valid $\mathrm{COC}$ on or before transfer. The prohibition on transfer is limited to the situation where the current $\mathrm{COC}$ is older than two years and the purchaser has not agreed to obtain a new certificate. Contrary views have been expressed (http://www.sapropertynews.com/electrical-certificates-ofcompliance/; http://www.fninc.co.za/publications/Electrical_Certificate of_Compliance.pdf accessed 2012-10-06) but it is submitted that they are incorrect.

(d) Regulation 7(5) imposes no prohibition on transfer if the COC is not older than two years. Transfer is also not prohibited in cases where the seller has no COC. This is not as strange as it may seem. A property owner (user) commits an offence if he or she is not in possession of a COC as stipulated in the Regulations, but this has no impact on the owner's ability to transfer ownership of the property. As stated above, the idea behind regulation $7(5)$ is that a COC older than two years may convey the impression that the electrical installation in question is safe, while in actual fact the possibility exists that it may not be the case. Hence the seller ought to be prohibited from potentially misleading the purchaser about the safety of the electrical 
installation by delivering to him or her a COC older than two years. Where the seller has no COC the possibility of misleading the purchaser does not arise.

The outcome of this is somewhat anomalous. In terms of the Regulations a property owner is prohibited from transferring the property if the current $\mathrm{COC}$ is older than two years and the purchaser has not agreed to obtain a new COC; however, the owner may proceed with transfer unrestricted if there is no COC. In the circumstances an owner wishing to escape from the prohibition on transfer may be tempted to simply destroy or invalidate the current COC, odd as it may appear. This may be particularly attractive for those owners who had obtained COCs without being obliged to do so because they are exempted in terms of regulation 7(3).

$\Theta$ The prohibition on transfer stipulated in regulation 7(5) is "subject to the provisions of section 10(4) of the Act" the latter Act being the Occupational Health and Safety Act 85 of 1993. Section 10(4) reads as follows:

"10 General duties of manufacturers and others regarding articles and substances for use at work

10(4) Where a person designs, manufactures, imports, sells or supplies an article or substance for or to another person and that other person undertakes in writing to take specified steps sufficient to ensure, as far as is reasonably practicable, that the article or substance will comply with all prescribed requirements and will be safe and without risks to health when properly used, the undertaking shall have the effect of relieving the first-mentioned person from the duty imposed upon him by this section to such an extent as may be reasonable having regard to the terms of the undertaking."

On the face of it, section 10 does not deal with electrical installations at all; it concerns "articles" and "substances". The expression "article" is not defined in either the Act or the Regulations. A "substance" is defined as "any solid, liquid, vapour, gas or aerosol, or combination thereof". An electrical installation is clearly not a "substance", but is it an "article"? Unless it can be brought within the meaning of "article" section 10(4) would not apply to electrical installations at all.

Even assuming that an electrical installation constitutes an article, it is not clear where this leads. In simplified terms section 10(4) exempts a seller of an article from the duties imposed on him or her by section 10 of the Act, provided the purchaser has undertaken in writing to take certain steps to ensure that the article will comply with the relevant health and safety requirements. The only duties imposed by section 10 on sellers of articles are the duties contained in section 10(1). This states that the seller of an article for use at work must ensure that the article is safe and without risks to health when properly used and that it complies with all prescribed requirements. What section 10(4) does is to exempt that seller (that is, a seller who sells articles for use at work) from the duties imposed by section 10(1) if the purchaser has undertaken to take over those duties. 
The seller of a building does not sell the building's components or fixtures individually. What is sold, in fact, is the land and the permanent improvements thereto. To make any sense of regulation 7(5), read with section 10(4) of the Act, one would have to adopt the approach that the seller of a building housing an electrical installation is at the same time entering into a sale agreement in respect of the electrical installation as such. Liberally interpreted regulation 7(5) therefore means that a seller of an electrical installation may not transfer ownership in the installation if the $\mathrm{COC}$ in respect of the installation is older than two years; however, the seller of an electrical installation used at work may transfer ownership in the electrical installation, whatever the age of the COC, if the purchaser has undertaken in writing to ensure that the installation complies with the required safety standards.

A more popular (and even more liberal) interpretation of regulation $7(5)$, generally followed in practice, is that a seller of any property (including residential properties) may transfer ownership of the building to a purchaser, even if the COC held by the seller is older than two years, provided the purchaser has undertaken in writing to obtain a new COC: http://www.snymans.com/news-1 accessed 2012-01-14; http://www.fninc. co.za/publications/Electrical_Certificate_of_Compliance.pdf; accessed 2012-10-06; http://www.meumannwhite.co.za/news-details/19/ accessed 2012-10-06; http://www.eepublishers.co.za/images/upload/ECA-SA-Safe ty-Legislation-EnforcementB.pdf accessed 2012-10-02. Presumably this is what the drafters of the Regulations had in mind, but failed to state clearly.

$\Theta$ It is not totally clear how the two-year period is to be calculated. It is obviously the difference between two dates, the one being the date of the COC. However, determining the latter date could be problematic since every $\mathrm{COC}$ has two dates, namely the date of signature by the registered person and the date of signature of the recipient (see Annexure 1 to the Regulations). If the two dates are the same no problem arises, but what if they are different? It is submitted that in such instances the age of the $\mathrm{COC}$ is to be determined by reference to the date of the registered person's signature, not the date of receipt by the recipient.

The second date is more problematic: is it the date of the transaction giving rise to the transfer of the property, the date of transfer itself, or some other date, such as the date of fulfilment of the suspensive conditions in the underlying agreement on which the transfer is based; the date when the transferor has signed the transfer documents, or the date when the transfer documents were lodged in the deeds office? In terms of regulation 7(5) the current $\mathrm{COC}$ may not be older than two years at the point in time when the owner "allow(s) a change of ownership". Change of ownership occurs on the date of registration in the deeds office, but it is arguable that the transferor allows that to happen on the date when the transfer documents are signed. If this line of reasoning is correct, regulation 7(5) is to be interpreted on the basis that a new COC must be obtained for the purposes of transfer if more than two years would have lapsed between the date when the registered person signed 
the current $\mathrm{COC}$ and the date when the transferor is to sign the transfer documents.

$\Theta$ Nothing in regulation 7(5) prohibits a prospective purchaser from making an offer on a property subject to the condition that the seller is to deliver to the purchaser a new $\mathrm{COC}$, whatever the age of the certificate currently held by the seller.

\section{Marketing of immovable property}

As mentioned above a number of property practitioners have taken the view, relating to the previous dispensation, that a seller may not even commence marketing a property without being in possession of a valid COC. Other practitioners have expressed the same opinion on the current position (http:// www.fninc.co.za/publications/Electrical_Certificate_of_Compliance.pdf; accessed 2012-10-06; http://www.snymans.com/news-1 accessed 2012-0114). These views appear to be based on section 22 of the Occupational Health and Safety Act 85 of 1993, which reads as follows:

"Subject to the provisions of section 10(4), if any requirement (including any health and safety standard) in respect of any article, substance, plant, machinery or health and safety equipment or for the use or application thereof has been prescribed, no person shall sell or market in any manner whatsoever such article, substance, plant, machinery or health and safety equipment unless it complies with that requirement."

It is submitted that this section affords no support for these views. As stated above, a person selling immovable property does not sell the individual components or fixtures of the property; what is sold is the land together with the permanent improvements thereon. More specifically, when it comes to the sale of buildings no seller or estate agent would be advertising for sale the electrical installation in the building and no prospective purchaser would be making an offer to purchase the electrical installation as such. There would be no sale agreement relating to the electrical installation and no price will be specified in relation to the installation separately from the overall purchase price. The sale agreement will not describe the electrical installation separately from the description of the property that is sold and will also not state anywhere that the seller is selling the electrical installation to the purchaser. In the circumstances it is far-fetched to say that a seller is marketing the electrical installation when the property is put up for sale, or that he or she is selling the electrical installation when the property is sold. Had the legislature intended section 22 to cover situations where machinery and articles are not marketed or sold as individual items but are by operation of law deemed to be part of a greater entity that is offered for sale, one would have expected it to say so in clear terms.

The website of an electricity firm describing itself as "a leader in the issue of the electrical compliance certificate" contains the following statement:

"You may not lease or rent out your property unless you possess a valid electrical compliance certificate for the electrical installation in that property. Tenants must be supplied with a copy of the certificate. Rental agents are now required to see the certificate before they will assist you with a tenant." 
The website furthermore proclaims that "we are constantly in touch with the Electrical Contractors Board and Association, as well as the Gauteng Electrical Inspectorate, to ensure that we deliver to you the most accurate Electrical Compliance Certificate possible" (http://www.Itcelectrical.co.za/ht $\mathrm{ml} /$ compliance.html accessed 2012-10-06). The paragraph quoted deserves no further comment, other than to say that there is nothing in the Occupational Health and Safety Act or the Regulations remotely supporting it. It illustrates the extent to which the Regulations are misunderstood in the electrical industry.

\section{Issue of certificates of compliance}

Only registered persons may issue COCs (reg 9(1)) after having satisfied themselves by means of an inspection and test that the electrical installation complies with the applicable safety standards or general safety principles (reg 9(2)). The latter regulation reads as follows:

“(2) A registered person may issue a certificate of compliance accompanied by the required test report only after having satisfied himself or herself by means of an inspection and test that -

(a) a new electrical installation complies with the provisions of regulation 5(1) and was carried out under his or her general control; or

(b) an electrical installation which existed prior to the publication of the current edition of the health and safety standard incorporated into these Regulations in terms of regulation 5(1), complies with the general safety principles of such standard; or

(c) an electrical installation referred to in paragraph (b), to which extensions or alterations have been effected, that -

(i) the existing part of the electrical installation complies with the general safety principles of such standard and is reasonably safe, and

(ii) the extensions or alterations effected comply with the provisions of regulation 5(1) and were carried out under his or her general control."

Two issues arise:

$\Theta$ Regulation 9(2) makes provision for the issue of COCs in three circumstances only, namely (a) in the case of a new installation; (b) where the installation existed prior to the publication of the current edition of the health and safety standard incorporated into the Regulations in terms of regulation 5(1), and (c) where extensions and alterations have been done to the installation referred to in (b). No provision is made for the issue of a COC in respect of an installation which is not new but existed at the time of, or was installed after, the publication of the current edition of the health and safety standard incorporated into the Regulations. A COC may well have been issued in respect of such installation at the time of its installation but, as will be seen below, a new COC has to be issued upon a change of ownership of the property in question if the current certificate is older than two years. Moreover, if the user of such installation alters or extends the installation a COC has to be obtained in respect of at least the addition or alterations (reg 7(4)), but no provision is made in regulation 9(2) relating thereto. 
$\Theta$ In terms of regulation 9(2)(a) a registered person may issue a COC in respect of a new installation only if such registered person has carried out the installation under his or her "general control". The same applies under reg 9(2)(c) in respect of the extensions or alterations concerned: the registered person issuing the $\mathrm{COC}$ must have carried out the alterations or extensions under his or her "general control". The underlying intention, apparently, is to stop consumers from getting unregistered persons to do the work and then engaging a registered person to issue the COC: see Greager April 2009 Vector 6. Provided there is proper policing this objective may well be achieved, considering that a registered person issuing a COC contrary to regulations 9(2)(a) and (c) commits an offence (reg 15). However, two aspects had been overlooked. Firstly, no provision is made for cases where the registered person who had attended to the installation or alterations/extensions is no longer in business and had omitted to issue a COC at the time when the work was done, or had in error issued an invalid certificate - who must issue the $\mathrm{COC}$ if the user now wishes to have one? Secondly, a property owner who had engaged a registered person to install an electrical installation or effect changes or extensions thereto would not necessarily be in a position to determine whether or not the work had been done under the registered person's "general control". A registered person is not required to do the work in person but may engage employees to do so provided they work under his or her general control (reg 5(4)). In terms of regulation 1 the expression "general control" includes "instruction, guidance and supervision" in respect of the work. This begs the question: is a COC issued by a registered person valid or void if it comes to light later that the work had in fact been done by persons employed by the registered person but not under his or her general control?

\section{Validity of certificates of compliance}

As stated earlier, users and lessors are obliged to have valid COCs in respect of electrical installations, or alterations and extensions thereto, in the circumstances described in regulations $7(1)$ and (3). In similar vein regulation $9(4)$ imposes a duty on any person undertaking to do electrical installation work to ensure that a valid COC is issued for that work. This begs two questions: firstly, what are the requirements for a valid $\mathrm{COC}$ and, secondly, under what circumstances (if any) would a valid COC become void? The following is submitted:

$\Theta$ A document not falling within the parameters of the definition of a $\mathrm{COC}$ in regulation 1 (see above) can never be a valid COC; in fact it is not a COC at all. Accordingly, at the very least a document qualifies as a valid COC only if it is

(i) a certificate with a unique number obtainable from the chief inspector, or a person appointed by the chief inspector;

(ii) in the form of Annexure 1; and

(iii) issued by a registered person in respect of an electrical installation or part of an electrical installation. 
$\Theta$ An important question is whether a document in the form of Annexure 1 is a valid $\mathrm{COC}$ if a registered person signs it without having performed the duties imposed by regulation 9(2). In other words, is every COC received from a registered electrician valid as long as it is in the form of Annexure A, properly filled in and signed? An affirmative answer would mean that a COC would be perfectly valid despite the fact the electrical installation to which it relates was completely unsafe at the time when the registered person signed the certificate. This could hardly have been the intention. Accordingly, it is submitted that a document qualifies as a COC only if a registered person lawfully issues it. A registered person who delivers to a user or lessor a signed document in the form of Annexure 1 cannot be said to issue a COC lawfully if such registered person signed the document

(a) without carrying out an inspection and test as prescribed by regulation 9(2);

(b) after performing an inspection and test without satisfying himself or herself that the electrical installation in question meets the applicable safety requirements stipulated in regulation $9(2)$; and/or

(c) without having done the electrical installation or the alterations / extensions in the circumstances contemplated by regulation 9(2).

In all these instances a document in the form of Annexure 1 would not be a valid $\mathrm{COC}$, in that a registered person had not lawfully issued it.

$\Theta$ A COC must be in the form of Annexure 1. The form in question contains blank spaces where the address details of the relevant electrical installation must be filled in, including the GPS co-ordinates. In addition the form makes provision for two declarations, one by the registered person who performed the required inspection and test, and the other by an electrical contractor declaring that the electrical installation has been carried out in accordance with the requirements of the Occupational Health and Safety Act, 1993, and the regulations made thereunder. Both declarations contain blank spaces to be filled in by the registered person and electrical contractor concerned. There are blank spaces for the parties' signatures and, in the case of the registered person's declaration, the date. At the end there are spaces for the recipient's name, signature and date. Under the registered person's declaration there are two notes, stating

"1. This certificate is not valid unless all the sections have been completed correctly and the test report in the format approved by the chief inspector is attached.

2. This certificate will be invalid if any corrections have been made."

It is safe to say that a document in the form of Annexure 1 is not a valid $\mathrm{COC}$ if the declarations in question had not been signed by the parties concerned. Arguably, the document is also an invalid COC if it had been signed but

(a) some blank spaces had not been filled in;

(b) all the blank spaces had been filled in but some incorrectly; 
(c) the registered person dated the form incorrectly;

(d) corrections had been made before or after the document was signed; and/or

(e) the required test report is not attached.

Literally interpreted any correction made to the details filled in on a COC invalidates the form, however trivial the correction might be. Accordingly, if a mistake had been made a new form must be filled in and signed.

$\Theta$ As a general rule a valid COC remains valid indefinitely, provided it is not amended (see below). It does not necessarily lapse if alterations and/or extensions are made to the electrical installation to which it relates. In such a case the user or lessor may obtain a new $C O C$ in respect of the whole installation but is not obliged to do so: regulation 7(4). If a COC is obtained in respect of the alterations and/or extensions only the earlier COC remains valid but only in respect of the original installation.

Although a COC remains valid indefinitely in the hands of the user or lessor to whom it was issued, it cannot on a change of ownership be transferred to a purchaser if it is older than two years (reg 7(5)) - see the discussion above.

The abovestated interpretation of what constitutes a valid $\mathrm{COC}$ has important consequences. Although users and lessors of electrical installations are entitled to insist that they be issued with valid COCs (reg $9(4)$ ), they may have some difficulty in knowing or verifying whether in fact the document handed to them constitutes a valid COC. To assist consumers in determining whether a registered person has signed or will sign the COC, the Regulations empower users and lessors to ask a registered person to produce his or her registration certificate (reg 11(4)). However, this will be helpful only to informed consumers who are aware of the need to ask for proof of registration and who know what the features of a valid registration certificate are. Others may be less informed and may not even know that they may and should ask for proof of registration, let alone what a valid registration certificate looks like. That aside, most consumers would probably not know whether or not the details filled in by the registered person on a COC are correct, or whether the registered person had signed the document only after carrying out a proper inspection and test. Similarly they may be unaware that the registered person had allowed his or her employees to attend to the installation or extensions/alterations without exercising any "general control" as required by regulation 9(2). Users or lessors may thus in good faith believe that they are in possession of a valid COC while in actual fact they are not. They may quite possibly escape criminal liability based on their good faith, but that is not the crucial issue. What is most disturbing is that consumers issued with COCs carry the risk that the documents handed to them by electricians could be valueless and cannot be relied on as confirmation that the electrical installation in question is safe. Persons particularly exposed to this risk are purchasers and lessees to whom COCs are transferred by sellers and lessors - how are they to know whether the certificates had been lawfully issued and signed by registered electricians? 


\section{Amendment of certificates of compliance}

No person may amend a COC: regulation 9(5). A contravention of this provision is an offence (reg 15) but it is not clear what effect an amendment may have on the validity of a COC. As stated above, a document containing corrections is not a valid COC, but not all amendments are necessarily corrections. For example, adding an additional clause to a COC in the form of Annexure A would constitute an amendment of the form without it being a correction. Presumably the intention is that a valid COC lapses when amendments are made to it at any stage after it has been issued.

\section{Lost or damaged certificates of compliance}

No provision is made in the Regulations for the substitution of lost or damaged COCs. The only option is to obtain a new one.

\section{Scope of certificates of compliance}

A registered person issuing a $\mathrm{COC}$ certifies that the electrical installation to which the COC relates complies with the applicable safety standard, general safety principles and/or is reasonably safe as the case may be (reg 9(2)). A $\mathrm{COC}$ is therefore proof that the minimum safety requirements in question have been met. There has been some debate on the internet as to whether a COC also constitutes proof that the electrical system is in working order. Some commentators have expressed the view that this was so under the previous dispensation, but no longer applies: http://www.property24.com/arti cles/electrical-compliance-made-simple/9613 accessed 2012-10-05; http:// www.sapropertynews.com/electrical-certificates-of-compliance/ accessed 2012-10-05. Others question whether it ever was the case (http://www.the forumsa.co.za/forums/showthread.php/7529-Misleading-articles-on-the-elec trical-COC accessed 2012-10-05) while a third group categorically declares that a COC "merely states that the electrical installation is safe and not necessarily that same is in working order" (http://www.snymans.com/faqs/ who-is-responsible-for-the-electrical-compliance-certificate).

It is submitted that, although a COC is primarily concerned with safety standards, it also conveys indirectly that the electrical installation to which it relates is in working order. Regulation 9(3) stipulates that, if at any time prior to the issuing of a certificate of compliance any fault or defect is detected in any part of the electrical installation, the registered person must refuse to issue such certificate until that fault or defect has been rectified. In other words, a COC can only be issued if there are no faults or defects in any part of the electrical installation. Logically, an electrical installation is by necessary implication in good working order if there are no faults or defects.

A registered person inspecting and testing an electrical installation for the purposes of issuing a COC is not required in terms of the Regulations to check the electricity supply to the property or to verify that the municipal electricity meter is functioning correctly and accurately reflects the electricity usage in the premises. The registered person also has no duty to test any of the electrical appliances connected to the plug points. Accordingly, the Regulations do not provide consumers with any assurance that they will be 
billed correctly for electricity consumed in the premises or that all appliances connected to an electrical installation in a building are in fact in working order. Whether or not a purchaser or lessee of a building can hold the seller or lessor liable for any fault in the supply of electricity to a building or defects in the electrical appliances included in the sale or lease, hinges on an application of the common law, the terms of the sale or lease agreement and, to the extent applicable, legislation such as the Consumer Protection Act 68 of 2008, the Housing Consumers Protection Measures Act 95 of 1998 and the Rental Housing Act 50 of 1999.

\section{Enforcement}

A user or lessor who fails to comply with the obligations imposed by the Regulations commits an offence: regulation 15. Upon conviction the offender may be fined or imprisoned for a maximum period of 12 months. In the case of a continuous offence an additional fine of R200 for each day on which the offence continues may be imposed; alternatively additional imprisonment may be imposed comprising one day for each day on which the offence continues. The period of such additional imprisonment may not exceed 90 days.

The wisdom of the enforcement mechanism has been questioned on the grounds that the Regulations "comprise first-world legislation which is out of touch with South African realities": Bertrand http://www.bowman.co.za/News -Blog/Blog/New-electrical-compliance-regulations-make-criminals-of-a-greatmany-South-Africans accessed 2012-10-05. The author points out that it is highly unlikely that the police and/or prosecuting authorities in South Africa have the capacity to investigate or prosecute offences of this nature given the level of far more serious crimes in this country. That apart it may be asked how the Regulations will be enforced in hundreds of thousands of dwellings in former black townships; in fact the outcome of the Regulations will simply be that "most of the dwellers in those townships will be contravening the Regulations by not having Certificates of Compliance and will technically be guilty of criminal offences".

There is much to be said in support of these contentions.

\section{Conclusion}

Nobody can seriously challenge the necessity of a regulatory framework to ensure the safety of electrical installations in buildings. Unfortunately a number of deficiencies, coupled with the confusion caused by bad drafting, cast a shadow over the Electrical Installation Regulations, 2009. Of major concern is the fact that consumers face the risk that COCs are worthless because the electricians that issued them had not complied with the prescribed procedures. The reality is that consumers generally accept COCs at face value, without questioning their validity. They cannot be expected to query the integrity of the person issuing the certificate, nor to supervise the work to ensure that the regulatory requirements are met. Imposing such duties on laypersons brings the credibility of the entire dispensation into question. 
The success of the current system hinges on proper policing and enforcement through the criminal courts, both being heavily strained as it is given the high level of serious crime in South Africa. However, finding an alternative, workable solution may be easier said than done. The key stakeholders are electricians, property owners (users), suppliers and inspection authorities, with financial institutions and property practitioners (estate agents and conveyancers in particular) playing a supportive role. Whatever system is designed will function satisfactorily only if each performs his/her respective duties properly and diligently. What may be considered is making it compulsory that a $\mathrm{COC}$, accompanied by proof of registration of the electrician issuing it, be delivered to a conveyancer before registration of any mortgage bond and/or transfer. Similarly, it could be made compulsory for lessors to furnish COCs to letting agents before they may accept mandates to find tenants. To encourage registration on the part of electricians, consideration should be given to a statutory provision whereby unregistered electricians are not entitled to remuneration for work performed by them. A provision to this effect is contained in the Estate Agency Affairs Act 112 of 1976, and it has proved to at least have some impact on limiting the proliferation of unregistered estate agents.

Henk Delport

Nelson Mandela Metropolitan University, Port Elizabeth 